\title{
A Suggestion on Product Model Driven Construction Robot
}

\author{
Naohiro Ikeda \\ Senior Researcher \\ Japan Construction Method \\ and Machinery R .I. \\ Fuji-si Sizuoka Pref. Japan
}

\author{
Syuji Ageishi \\ Vice Manager \\ Japan Construction Method \\ and Machinery R .I. \\ Fuji-si Sizuoka Pref. Japan
}

\author{
Hiroshi Yamamoto \\ Research Coodinator \\ Public Works Research Inst. \\ Tukuba-si Ibaraki Pref. Japan
}

\begin{abstract}
The great majority of robot construction machine currently in service are remotely controlled with the help of video information. Most of these robots are connected to remote-control cameras. In certain circumstances, video images of these robot systems cannot provide clear relative positional relationship between the topography where the job is being done and the device at the top end of the machine, resulting in a degradation in operating efficiency. On the other hand, dangerous situations that potentially involve secondary accidents will be encountered if the survey team approaches the site where soil collapse or building breakdown has occurred for the purposes of survey and of laying the work markers. Against such a background, there is a demand for construction robots that could make the best use of information about the design, the present topographic features, and so on.

It is intended herewith to establish a robot construction system that controls a top-end device in accordance with an expected trajectory of the backhoe tip, which is generated based on present topographic features and design form (target of work) in Japanese coordinate system.

This paper describes a 3D simulation software that is installed to generate command values by which the robot machine, typically a hydraulic shovel, actuates the top-end device. This actuation is effected depending on the machine's boom and arm angles that are calculated through inverse kinematics from the coordinates of the bucket tip.
\end{abstract}

Keywords: Robot construction machine, top-end device, 3DCAD, product model

\section{INTRODUCTION}

Automation in the construction sites is showing a rapid progress in accordance with the evolution in the computer technology. However, only a few examples of construction robots using the product model are available and the extent of the application of the product model is limited to providing the operator with information, restricting the range of the work area and such. In developing the backhoe automated system, role assignment between man and machine is defined and then the automated hydraulic shovel has been developed by taking full advantage of the product model. This example of the development is explained in this paper.

\section{TABLE-1 ROLE ASSIGNMENT IN MAN-MACHINE SYSTEM}

\subsection{Cognitive Engineering Interface Model}

The recent cognitive engineering is proposing the "human-centered design " that gives heed to the relation between man and machine from an operator's point of view. When interactions between man and machine are made more suitable for man's recognition and decision, it is expected that human error will be reduced and, in the event of occurrence of any problem, the operator will be able to cope with it more efficiently. This is the reason why the human-centered design is advocated.

As opposed to automation in production lines in a factory, automation in the civil engineering requires an increased number of actions against problems (as well as pointed judgment of the situation). Thus, the operator's efficiency to take actions gives significant impact on the entire operating efficiency. Aside from trying to develop the complex autonomous control, it seems possible to develop the simple autonomous control system that could improve the operating efficiency by delegating to the operator the tasks that lie in the area of his or her responsibility.

\subsection{Job Analysis of Hydraulic Shovel and Scope of Development}

Job to be done by the hydraulic shovel are broadly divided into the traveling, excavating and loading operations. During travel, the machine does not perform excavating and loading operations. On the other hand, it does not travel during excavation and loading. In addition, most tasks are excavating and loading operations and the similar tasks will be repeated. Therefore, the scope of the tasks in this development is limited to the excavating and loading operations. In these two operations, it is assumed that operator takes charge of the finishing stake and confirmation of topographic features, and the excavating and loading operations are assigned to the machine. 


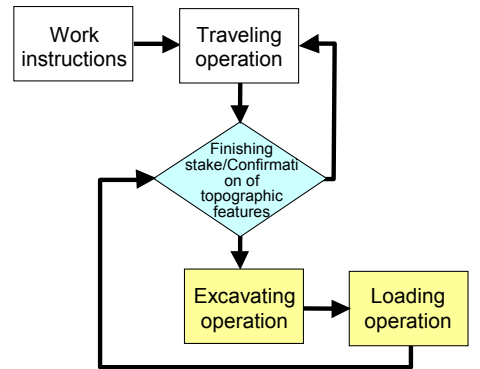

Figure 1 Job analysis of hydraulic shovel and scope of development

\subsection{Job Analysis in Scope of Development}

The present jobs during the excavating and loading operations are analyzed in detail to define the role assignment in the man-machine system. In this section, the work scenario in the system development is described and the role assignment in the man-machine system is listed.

(1) Finishing stake and confirmation of present topographic features

The operator should understand the product model and the present topographic features through the man-machine interface to select the excavation pattern. Also the operator selects the excavation start point within the excavating operation area.

(2) Bringing the bucket tip to the excavation start point The system generates an expected tip trajectory that connects the present tip position coordinates to the excavation start point coordinates predetermined by the operator over the shortest distance possible (with a linear line) and controls the valve on each cylinder so that the bucket tip can reach the target point. The angle of the bucket tip is automatically set up based on the design form or excavating pattern.

(3) From excavating operation to scooping operation The system generates the optimal excavation trajectory and automatically performs the excavating operation. The excavation trajectory is calculated to meet the depth of excavation decided by the operator. The operator arbitrarily changes the depth of excavation when he or she senses a decrease in excavation speed. Then the system re-generates the optimal excavation trajectory.

(4) Swiveling operation

The system automatically sets up the target of swiveling motion based on the dump truck position, the machine position and the azimuth angle of the upper swiveling structure, and rotates this structure through the azimuth angle until it reaches the target position by controlling the swiveling motion valve.

(5) Bringing the bucket to the unloading position

The system automatically determines the unloading position based on the dump truck position, the azimuth of the machine and the frequency of loading operations, and generates the trajectory to the dump truck position. The system controls (opens and closes) the valve to bring the bucket to the unloading position at the dump truck position according to the trajectory generated.

(6) Unloading operation

The system actuates the bucket at the unloading position to dump the excavated soil onto the dump truck. The operator monitors the unloading operation and controls its speed. Upon completion of this step, the operator returns to step (1).

Table 1 Role Assignment in Man-Machine System

\begin{tabular}{|c|c|c|}
\hline Phase & Man & System (Machine) \\
\hline $\begin{array}{l}\text { (1) Finishing stake } \\
\text { and } \\
\text { Confirmation of } \\
\text { present } \\
\text { topographic } \\
\text { features }\end{array}$ & $\begin{array}{l}\text { - Decision on } \\
\text { excavating pattern } \\
\text { - Decision on } \\
\text { excavation start } \\
\text { point }\end{array}$ & \\
\hline $\begin{array}{l}\text { (2) Bringing bucket } \\
\text { tip to the } \\
\text { excavation start } \\
\text { point }\end{array}$ & & $\begin{array}{l}\text { - Generation of excavation } \\
\text { trajectory } \\
\text { - Operation control } \\
\text { - Setup of bucket angle }\end{array}$ \\
\hline \begin{tabular}{|l|} 
(3) From excavation \\
to scooping \\
operation
\end{tabular} & $\begin{array}{l}\text { - Modification of } \\
\text { excavation } \\
\text { parameters }\end{array}$ & $\begin{array}{l}\text { - Generation/Re-generation } \\
\text { of excavation trajectory } \\
\text { - Operation control }\end{array}$ \\
\hline $\begin{array}{l}\text { (4) } \begin{array}{l}\text { Swiveling } \\
\text { operation }\end{array} \\
\end{array}$ & & $\begin{array}{l}\text { - Setup of target swiveling } \\
\text { motion } \\
\text { - Operation control }\end{array}$ \\
\hline $\begin{array}{l}\text { (5) Bringing bucket } \\
\text { to unloading } \\
\text { position }\end{array}$ & & $\begin{array}{l}\text { - Setup of unloading position } \\
\text {-Operation control }\end{array}$ \\
\hline $\begin{array}{l}\text { (6) Unloading } \\
\text { operation }\end{array}$ & $\begin{array}{l}\text {-Modification of } \\
\text { unloading speed }\end{array}$ & $\begin{array}{l}\text { - Generation of unloading } \\
\text { operation } \\
\text { - Operation control }\end{array}$ \\
\hline
\end{tabular}

In the next chapter, the procedure for generating the expected bucket tip trajectory is described, which is necessary to assign the foregoing roles.

\section{HYDRAULIC SHOVEL OPERATION CONTROL}

\subsection{Operation Control with Product Model}

Operation of the hydraulic shovel is controlled using the two coordinate systems. In the first place, the operator understands the conditions of the product model as well as the present topographic features through the man-machine interface, and at the stage of designating the excavation start point, the site coordinate system (X, Y and $\mathrm{Z}$ space coordinate system) is used. Therefore, the system controls the swiveling motion in the site coordinate system when it intends to bring the bucket tip to the excavation start point. In the present excavating operation, the operator performs the excavating operation along the design lines while watching the finishing stake and does the shaping operation while facing normal to the design lines. The orientation of excavating operation with the robot construction machine is effectively selected by using the product model. The use of the site coordinate system could define the relationship between the position of the construction robot and the design form. 
In the excavating operation, the machine is controlled in the machine body coordinate system that is in the vertical cross section and includes both the excavation start position and the construction robot position. Since the swiveling motion cannot be done during the excavation operation, the shovel motion can be defined in the biaxial plane coordinate system that facilitates the boom/arm control by using the inverse kinematics which will be described later. Since the product model is defined in the space coordinate system, the coordinate conversion in any vertical cross section is feasible, allowing a simple definition of design boundary in the body coordinate system. Thus, automatic control of the shaping operation along the design shape will be enabled.
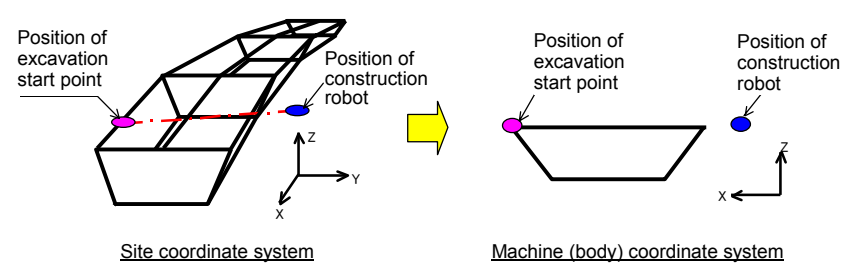

Figure 2 Conceptual Drawing of Coordinate System Conversion in Operation Control

\subsection{Boom/Arm Control with Inverse Kinematics}

Motion of the hydraulic shovel is placed under the PID control of the boom and arm angles of the hydraulic shovel. These angles are found from the shovel tip target position that is obtained by applying the inverse kinematics on the basis of an expected tip trajectory generated beforehand. With definition of the expected tip trajectory, it becomes possible to successively define the target positions and to control the excavating operations. The basic equations of the forward kinematics are given hereunder:

$$
\begin{aligned}
& \mathrm{x}=\mathrm{L} 1 \cos \theta 1+\mathrm{L} 2 \cos (\theta 1+\theta 2)+\mathrm{L} 3 \cos (\theta 1+\theta 2+\theta 3) \\
& \mathrm{z}=\mathrm{L} 1 \sin \theta 1+\mathrm{L} 2 \sin (\theta 1+\theta 2)+\mathrm{L} 3 \sin (\theta 1+\theta 2+\theta 3) \\
& \theta=\theta 1+\theta 2+\theta 3
\end{aligned}
$$

Given the definition of the tip target positions ( $\mathrm{x}$ and $\mathrm{z}$ : expected trajectory) and the bucket angle $\left(\theta_{3}\right)$, it becomes possible to solve the inverse kinematics equation, leading to determination of the boom angle $\theta_{1}$ and arm angle $\theta_{2}$. The bucket angle is the angle made between the arm and the line connecting the bucket link to the tip position.

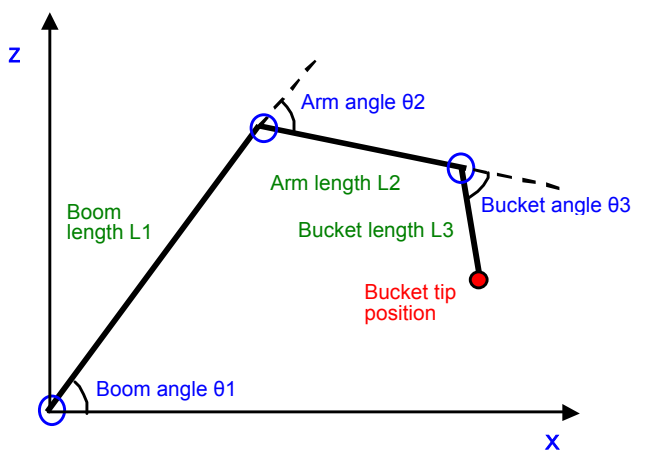

Figure 3 Definition of Operation Control Basic Equation

\subsection{Operation Modes}

The excavating operations of the hydraulic shovel have several modes of operation that will be selected based on the details of the operation, and the rules for generating the expected tip trajectory are preset for each mode. The operator can select one of the modes to be consistent with the details of the operation.

These modes as well as their outlines are explained in the rest of this section.

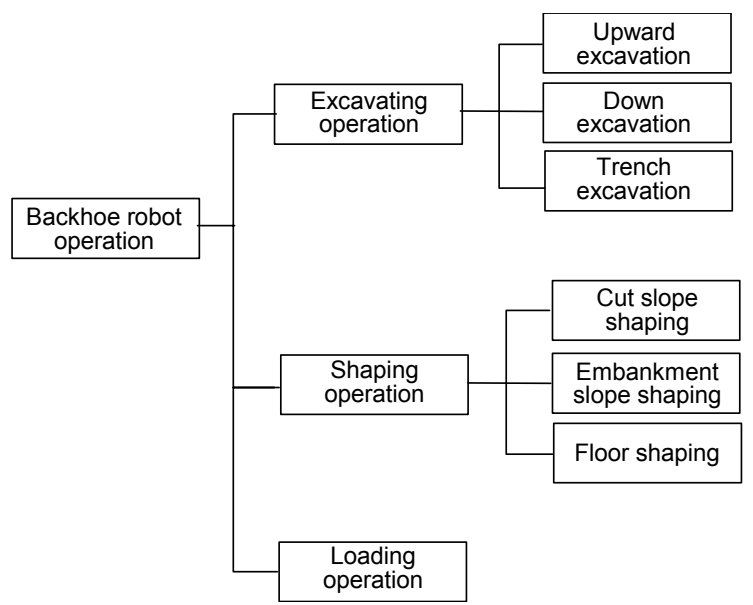

Figure 4 Operation Modes

(1) Excavating operations

In the excavating operations, it is required to generate a highly efficient excavation trajectory within the design excavation range. For better efficiency, the excavation operation is broadly divided into the upward excavation mode, downward excavation mode and trench excavation mode. In the upward excavation mode, the excavated soil drops down to the ground by gravity. Therefore, the trajectory is designed such that the soil is scraped down to the scooping position and then, at the end of the operation, it is held in the bucket. On the contrary, in the downward excavation mode, there is the need for designing the trajectory by which the shovel keeps excavating the soil while holding excavated soil in the bucket. In the trench excavation mode, the trajectory is generated as a function of the depth of excavation and the length of horizontal pull. The optimal angle of the bucket tip is set up in the trajectory depending on each excavation pattern and the soil property. This angle is defined as the angle made between the bucket bottom plane and X-axis.

(2) Shaping operation

In the shaping operation, the trajectory is basically generated such that the bucket tip can trace the design shape lines. The angle of the bucket tip is preset such that the bucket bottom plane can be in parallel with the gradient of the slope. 


\subsection{Rules to Generate Expected Tip Trajectory}

The hydraulic shovel control pattern is divided into an excavating mode and a traveling mode. In the excavating mode, the bucket is controlled while it is on the ground, and in the traveling mode, the bucket is controlled while it is above the ground.

(1) Traveling mode control

In the traveling mode control, the trajectory is designed to link the target points with a straight line for the better working efficiency. When there is any obstacle on the linear trajectory, the position of that obstacle should be also taken into account in designing the trajectory.

The traveling mode control is composed of the following elements of motions:

- Traveling from standby attitude to excavation start point

- Traveling from completion of scooping to loading position

- Traveling from completion of loading to standby attitude

(2) Excavating mode control

The rule to generate the expected tip trajectory in the excavating mode control is that the shortest geometrical excavating trajectory connected to the target should provide the highest excavation efficiency. But when an excavation resistance is significant, the traveling speed on the expected trajectory will be lowered, resulting in the excavation efficiency being decreased. Therefore, the operator should visually monitor the progress of excavation operation at the site and, if deemed appropriate, modify the excavating pattern and excavating parameters to select the optimal pattern.

\subsection{Basic Excavating Patterns}

The basic excavating patterns are grouped according to the cylinders used in excavation. The operation in each basic excavating pattern is described below.

(1) Cutting operation

As to the operation that cuts the soil from the excavation start point, a driving force is gained from the bucket cylinder. The change of the depth of excavation is also made by the force of the bucket cylinder.

(2) Horizontal pull operation

When the bucket tip reaches the prescribed depth, the horizontal pull operation is requited until the bucket capacity is met. During the horizontal pull operation, the angle of the bucket tip is kept constant and the soil is excavated by the force of the arm cylinder.

(3) Scooping operation

The soil is excavated again by the force of the bucket cylinder just before the scooping operation when the soil excavation resistance becomes largest. When the top face of the bucket becomes horizontal, the excavated snil is sconned un with the honm cylinder.

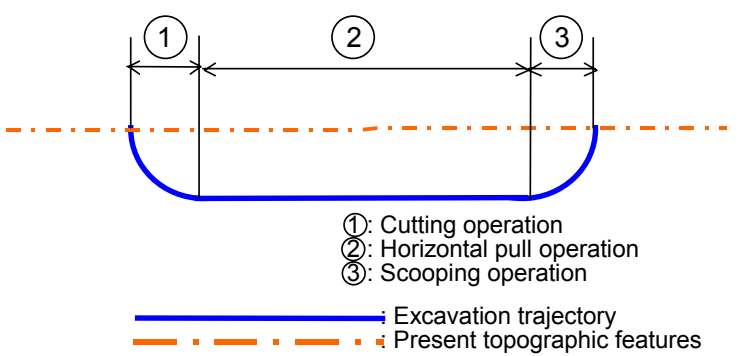

Figure 5 Basic Excavating Patterns

\subsection{Parameters of Expected Excavating Trajectory}

The expected excavating trajectory is preset geometrically with the aim of improving the working efficiency. When the excavation capability of the hydraulic shovel is sufficiently larger than the excavation resistance, it is most effective to make the expected excavating trajectory as short as possible in order to shorten the length of time required by excavation. Therefore, as illustrated in Figure 6 (figure at the left side), the expected excavating trajectory should be semicircular. The larger the excavation resistance, the lower the excavation speed, resulting in a lower working efficiency. If such is the case, the excavation resistance should be decreased by making the excavation depth smaller. Then it is necessary to increase the length of horizontal pull in order to keep the amount of the excavation constant. In this operation, the area swept by the trajectory is kept constant and the expected excavating trajectory is generated, thereby precluding the possibility of unnecessary excavation.

Parameters to generate the expected excavating trajectory are angle of bucket tip, depth of the excavation and length of horizontal pull, where the angle of bucket tip and length of horizontal pull are changed in conjunction with the depth of the excavation.

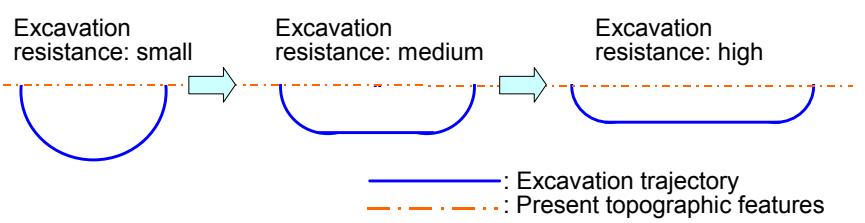

Figure 6 Rules to Generate the Excavation Trajectory 


\subsection{Depth of Excavation}

The depth of excavation should be preset using the following two steps:

(1) Approximate depth determined by the dipper coefficient

The approximate depth of excavation is determined by the dipper coefficient $\mathrm{K}_{2}$. The operator pre-defines the depth of excavation according to the dipper coefficient $\mathrm{K}_{2}$. The correlation (function) between the depth of excavation and the dipper $\mathrm{K}_{2}$ should be obtained in the future.

(2) Fine tuning by the operator

The operator monitors the excavation speed and continuously fine-tunes the depth of the excavation as appropriate according to the excavation speed.

Table 2 Dipper Coefficient $\mathrm{K}_{2}{ }^{[1]}$ Dependent on Soil Property

\begin{tabular}{|c|c|c|c|c|}
\hline $\begin{array}{l}\text { Severity of } \\
\text { work }\end{array}$ & $\begin{array}{l}\text { Easy to } \\
\text { excavate }\end{array}$ & $\begin{array}{l}\text { Relatively } \\
\text { easy to } \\
\text { excavate }\end{array}$ & $\begin{array}{l}\text { Slightly difficult } \\
\text { to excavate }\end{array}$ & $\begin{array}{l}\text { Difficult to } \\
\text { excavate }\end{array}$ \\
\hline Soil property & $\begin{array}{l}\text { Packed soil, } \\
\text { dry and fine } \\
\text { earth and } \\
\text { sand, loose } \\
\text { soil, sandy } \\
\text { clay, finely } \\
\text { crushed rock }\end{array}$ & $\begin{array}{l}\text { Material that } \\
\text { can be crushed } \\
\text { without } \\
\text { blasting but } \\
\text { becomes } \\
\text { porous when it } \\
\text { is crushed, } \\
\text { clay, small } \\
\text { granulated } \\
\text { gravel, com- } \\
\text { pact soil }\end{array}$ & $\begin{array}{l}\text { Material that can } \\
\text { be crushed with } \\
\text { light blasting, } \\
\text { Finely cracked } \\
\text { limestone and } \\
\text { sandstone, damp } \\
\text { clay, conglom- } \\
\text { erate with } \\
\text { cobblestones }\end{array}$ & $\begin{array}{l}\text { Blasted rock, } \\
\text { bulky porous } \\
\text { material, hard } \\
\text { shale, limestone, } \\
\text { granite, } \\
\text { sandstone, } \\
\text { conglomerate, } \\
\text { till (Stiff clay) }\end{array}$ \\
\hline $\begin{array}{l}\text { Dipper } \\
\text { coefficient } \\
\mathrm{K}_{2}\end{array}$ & 0.95 to 1.0 & 0.85 to 0.90 & 0.70 to 0.80 & 0.50 to 0.70 \\
\hline
\end{tabular}

\subsection{Angle of Bucket Tip}

In the excavation work, the angle of the bucket tip is dependent on the soil property (soft or hard). Empirically, a comparably large angle of bucket tip is preferred for soft soil to complete the excavation work at a relatively short excavating distance, and a smaller angle is applied to hard soil to reduce the excavation resistance. However, it is asserted ${ }^{[2]}$ that a larger angle of the bucket tip is effective when the soil is too hard for the tip to bite into. Like the depth of excavation, the angle of the bucket tip is determined according to the dipper coefficient.

The angle is preset in the shaping operating such that the bucket bottom plane has the same gradient as the design plane. However, the movement is predetermined such that the bucket bottom plane does not interfere with the design plane at the inflection point of the gradient. The motion of the bucket tip is checked in the body coordinate system with the following 3D simulation.

\section{3D SIMULATION}

In order to verify the motion of the hydraulic shovel under control of the excavating trajectory that is designed as described in the above section, a 3D simulation prior to the demonstration using the hardware. In this software, the hydraulic shovel is modeled based on the drawings of the shovel precisely in the $3 \mathrm{D}$ space, and at the same time design shape as well as topographic features were also modeled in the $3 \mathrm{D}$ space in order to confirm the excavation motions and excavation conditions controlled by the packet trajectory. The motions of the boom, arm and bucket, which are controlled with the expected excavating trajectory was visualized in the $3 \mathrm{D}$ space using this software, and the validity of the rules to design the trajectory has been confirmed in terms of design shape and operation conditions. The sample of display shown with this simulation software is shown in Figure-7.

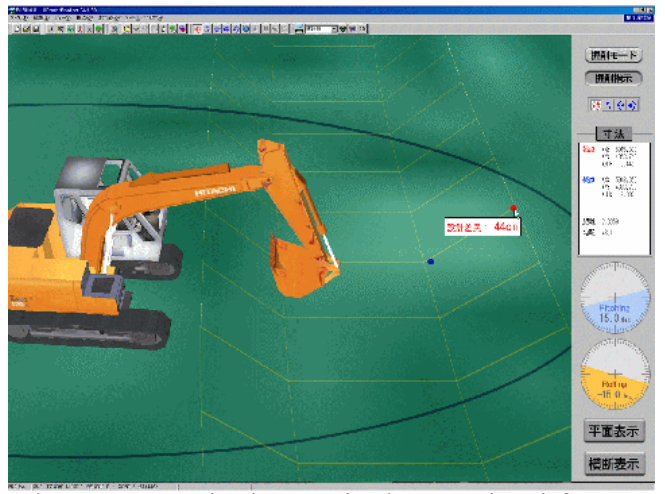

Figure-7 Typical 3D Display Derived from Simulation Software

\section{CONCLUSION}

Knowledge obtained from this development and review of the product model driven robot construction machine are summarized hereunder:

(1) Role assignment in the man-machine system is determined based on the task analyses.

(2) Rules to design the expected excavating trajectory are proposed to control the tip of the hydraulic shovel.

(3) The designed trajectory of the hydraulic shovel is checked against the design and topographic features using the 3D simulation.

The current study was conducted on the basis of the knowledge that has been gained from the General Technology Development Project called "Development of IT-Assisted Construction System Based on Robots, etc." undertaken by the Ministry of Land, Infrastructure and Transport. The General Laboratory of Construction Technology of Japan Construction Method and Machinery Research Institute has come up with a new proposal on development of the related technologies. We intend to 
continue our research work through exchange of views with the Public Works Research Center.

\section{REFERENCES}

[1] Akira Kohono et al.: "Implementation of Work" in Civil Engineering Series, Volume 16, pp. 65 - 67.

[2] Japan Construction Method and Machinery Research Institute: Construction Machine Handbook for Excavation, Transport and Foundation, pp. 114 - 125. 